\title{
O ideário de António Castro Fernandes na consolidação da experiência corporativa portuguesa
}

\author{
António Castro Fernandes' ideas in the consolidation of the Portuguese corporative \\ experience
}

\section{Leonardo Aboim Pires}

Centro de Estudos Interdisciplinares do Século XX da Universidade de Coimbra leonardopires5@hotmail.com

\begin{abstract}
Resumo: O presente estudo pretende analisar e compreender as ideias que guiaram a atuação de António Castro Fernandes durante o Estado Novo (1933-1974), destacando a sua importância na formação do corporativismo português. Além da crítica aos erros do regime liberal, Castro Fernandes destacou-se pela aproximação ao modelo italiano, a sua perceção da esfera pública e a interação entre trabalho, quotidiano e propaganda. Por outras palavras, fazendo uso de uma abordagem exploratório-descritiva a partir de obras impressas e cartas particulares, este estudo procura descortinar as razões para a sua posição ideológica e como este concebia o corporativismo enquanto teoria, enquadrandoo no contexto da cronologia política do seu tempo.
\end{abstract}

Palavras-chave: Fascismo, Corporativismo, Estado Novo, António Castro Fernandes.

\begin{abstract}
The present essay aims to evaluate the ideas that guided the action of António Castro Fernandes during the Estado Novo (1933-1974), stressing its relevance for the emergence of the Portuguese corporatism. Apart from the criticism of the mistakes of the liberal regime, Castro Fernandes was prominent because of its particular approach to the Italian model, his understanding of the 'public sphere' and the interaction between labour, everyday life and propaganda. In other words, using an exploratory-descriptive boarding from printed texts and private letters, this study seeks to unveil the reasons for its ideological position and to understand the meaning of the corporatism from his point of view, framing it in the political chronology of his time.
\end{abstract}

Keywords: Fascism, Corporatism, Estado Novo, António Castro Fernandes. 


\section{Introdução}

António Júlio de Castro Fernandes (1903-1975) foi uma das figuras estruturantes na emergência e consolidação do Estado Novo português, tendo militado, ainda jovem, nas correntes da direita antiliberal que surgiram no final da I República. O seu percurso profissional e político entrecruzou-se com os caminhos percorridos na construção do regime corporativo, destacando-se a sua presença como procurador à Câmara Corporativa (1935-1938; 1957-1965; 1969-1974) e em organismos de coordenação económica, tendo presidido a Federação dos Vinicultores do Centro e Sul de Portugal (1935-1937) e foi vogal da Comissão Reguladora do Comércio de Bacalhau (1938). Conta-se também a sua participação nos primeiros anos de atividade de duas instituições centrais no processo de corporativização em Portugal: o Instituto Nacional do Trabalho e Previdência (INTP) e a Fundação Nacional para a Alegria no Trabalho (FNAT). Como corolário deste itinerário, ocupou a Subsecretaria de Estado das Corporações e Previdência Social, entre 1944 e 1948, reconhecimento do trabalho dos anos anteriores em que, de acordo com Franco Nogueira, "se afirmara uma inteligência viva" (NOGUEIRA, 1978: 547). Nos anos seguintes, seria ainda Ministro da Economia (1948-1950) e presidente da Comissão Executiva da União Nacional (UN) (1958-1961; 1965-1968), cargos nos quais continuou a imprimir o seu empenho na continuidade do regime.

Ao rol de funções exercidas em pontos nevrálgicos da estrutura do salazarismo, alia-se uma constante atividade de escrita, destacando-se os textos produzidos sobre o corporativismo. É na súmula destes que faremos a nossa análise seguidamente, assinalando a sua importância e contributo para o que poderia designar-se a "escola corporativa" portuguesa.

Indiscutivelmente, Castro Fernandes encontra-se entre um escol de fiéis que acompanhou as várias fases do regime. A figura que se analisará nas próximas páginas abarca estas mesmas valências, através do exercício de vários cargos, a participação e importância conferida à imprensa e as várias obras e textos por si escritos. Este ensaio visa analisar duas facetas - a de ideólogo e a de político - revisitando, exclusivamente, o seu pensamento corporativo, em estreita associação com a evolução da sua carreira. Embora não se trate de um exercício biográfico scrito sensu, é possível entender a história biográfica como uma "ocasião para desfazer entrelaçados históricos maiores do 
que a personagem e com os quais ela interagiu" (FORTI, 2016: 126). Partindo desta fórmula historiográfica, pretende-se, através do pensamento deste indivíduo, fazer uma leitura global dos significados da direita política antes e durante o Estado Novo.

Como referimos, a invocação desta conduta metodológica não se inscreve numa tentativa em realizar um escrutínio definitivo da figura de Castro Fernandes, deixando alguns tópicos por analisar, por exemplo, o seu papel na conduta da UN nos anos finais do Estado Novo. Assumindo esta preocupação, importa atentar que "o processo histórico é a soma das ações humanas, a melhor maneira de entendê-las é precisamente estudando os atores por trás dessas ações" (SARDICA, 2013: 393). A análise da agencialidade das figuras inscritas em contextos passados e a procura da compreensão das suas ações encontra no posicionamento ideológico destas, associada à sua produção intelectual e à atividade política, uma hipótese de trabalho.

Reivindicando a ancoragem de um sistema de pensamento na vida de um ator histórico, pode ser feita uma análise que sustente o entendimento das suas atitudes. Recuperando os modos de pensar, tornar-se-á mais percetível seguir certos percursos de vida, atestando, no balanço final produzido pelos historiadores, contradições e simetrias, evoluções ou involuções em determinadas biografias. Estas potencialidades explicativas podem ajudar a superar o determinismo baseado na "ideia de que todos os homens, e especialmente os grandes homens, são essencialmente o produto da sua circunstância e, portanto, em maior ou menor medida, dominados por ela" (MARTINS, 2004a: 399).

A nível documental, como fontes principais para este artigo, duas vertentes foram consideradas. Num primeiro plano, foram analisadas as obras publicadas e discursos da autoria de Castro Fernandes. Além disso, foi feito o estudo da sua correspondência particular com Oliveira Salazar e Marcello Caetano ${ }^{1}$, presente no Arquivo Nacional da Torre do Tombo, de forma a auscultar o diálogo direto com os principais líderes do regime. De notar que a prática epistolar privada impõe uma estratégia discursiva com o destinatário e uma certa construção de si, impondo uma relação entre público e privado. O trabalho de crítica exigido para este artigo passou por perceber que estes documentos não referem o que houve, mas sim transmitem como o autor vivenciou e experienciou determinado evento.

O que se segue trata-se, assim, de uma reflexão sobre a natureza do fascismo português, encontrando, nos seus principais interlocutores, indícios e fundamentos

\footnotetext{
${ }^{1}$ Agradecemos ao Dr. Miguel Caetano a autorização concedida para a consulta desta documentação.
} 
teóricos como sustentáculo ideológico de uma cultura política fascista ${ }^{2}$. O que aqui se apresenta é um estudo ideográfico, na medida em que "considera as ideias no contexto epocal da sua gestação, consolidação e desenvolvimento dentro de determinada sociedade" (MESQUITA, 2007: 11). Pretende-se contribuir, não apenas para uma clarificação sobre as formulações teóricas realizadas em torno da ideia corporativa em Portugal, mas, igualmente, compreender o papel de alguns agentes no lançamento das bases do regime autoritário, no plano das ideias e na gestão da praxis políticoadministrativa.

\section{Do Nacional-Sindicalismo ao Salazarismo}

António Júlio de Castro Fernandes nasceu em Lisboa, a 2 de junho de 1903. Durante a sua juventude militou em vários grupos e movimentos de cariz antiliberal no período final da I República. Enquanto estudante universitário, no Instituto Superior de Comércio, onde se licenciou em Economia, foi presidente da Assembleia-Geral (1926) e, mais tarde, da Federação Académica de Lisboa (1926-1928) ${ }^{3}$. Foi um dos membros da Comissão Académica de Propaganda de Lisboa da Cruzada Nacional D. Nuno Álvares Pereira e, nessa qualidade, liderou, com outros, as movimentações grevistas no ensino superior entre janeiro e maio de 1926. Note-se que o seu percurso ideológico encontra similitudes com outros destacados dirigentes do Estado Novo, como Marcello Caetano (BARBOSA, 2015; MARTINHO, 2016), Pedro Theotónio Pereira (MARTINS, 2004b) ou João Pinto da Costa Leite (Lumbrales) (PIRES, 2016). Todos eles gravitaram em torno dos movimentos da direita nacionalista que pontuavam o cenário político dos anos 20 e que, posteriormente, adeririam sem reservas ou seriam cooptados no esforço de construção institucional do autoritarismo português. Poder-seia acrescentar que estas figuras, através do seu ativismo nas alterações no corpo político e da oposição à república parlamentar, ajudariam a que, em Portugal, como em outros países da Europa, "o liberalismo está prestes a fechar as portas dos seus templos desertos" (MUSSOLINI, 1933: 48).

\footnotetext{
${ }^{2}$ Seguimos a seguinte definição de cultura política: "os conjuntos de símbolos e significados ou estilos de ação que organizam reivindicações políticas e a formação de opinião por indivíduos ou coletividades" (LICHTERMAN; CAFAI, 2006: 392).

${ }^{3}$ Entre julho de 1927 e janeiro de 1928, enquanto Castro Fernandes ocupava a presidência da Federação Académica, a Assembleia-Geral tinha como presidente Marcello Caetano, enquanto estudante de Direito.
} 
O período entre a instauração da ditadura militar, em 1926, e a ascensão de Oliveira Salazar ao poder como Presidente do Conselho de Ministros, em 1932, pautouse por uma dispersão das forças conservadoras da direita. Todavia, como Marcello Caetano referiu nas suas memórias, "o surto fascista não deixou, porém, de impressionar a juventude portuguesa" e "aproveitando a impaciência juvenil surgiu então um movimento chamado Nacional Sindicalismo" (CAETANO, 1977: 69-70). Este movimento apresentou-se como "uma forte tentativa para impor a via da revolução pacífica com caudilhismo civil milicial e mobilização das massas” (LEAL, 1999: 249). Este voluntarismo, combinando uma ação política voltada para as massas, levou à adesão de várias figuras da direita nacionalista. Porém, dada a ameaça que constituíam para Salazar, foi empreendida uma célere ação para terminar com o movimento.

Para Filipe Ribeiro de Meneses, "Salazar dividiu o movimento seduzindo-o com o chamariz do poder real, reconhecendo a facção mais moderada dentro da organização como a face aceitável do nacional-sindicalismo" (MENESES, 2010: 153). É possível encontrar vários nacional-sindicalistas que iriam aderir ao novo regime para exercerem esse "poder real". Castro Fernandes não seria exceção, tendo sido convidado, em outubro de 1933, para ocupar o lugar de assistente no INTP. Na carta de agradecimento a Salazar pelas funções que iria desempenhar, considerava que este era "um lugar de primeira fila na linha de combate, um lugar-alvo, um lugar sem comodidades, um lugar de dura e áspera luta"4, situação para a qual contribui Pedro Theotónio Pereira. Nomeado por Salazar como Subsecretário de Estado das Corporações e Previdência Social, Theotónio Pereira acabaria por convidar alguns nacional-sindicalistas para colaborar no projeto de construção do corporativismo ${ }^{5}$, ideia, aliás, já lançada anteriormente $^{6}$. Um deles seria Castro Fernandes que, com Amaral Pyrrait e Abílio de Lemos, aceitaram tal missão de forma imediata. Estas figuras seriam responsáveis "por integrar os dissidentes fascistas no regime, fazendo a ligação entre o grupo Revolução Nacional e os Sindicatos Nacionais" (PINTO, 1994: 250). Nas palavras de Castro Fernandes, esta era uma passagem considerada quase como natural:

\footnotetext{
${ }^{4}$ FERNANDES, António Júlio de Castro (1933). Carta a António de Oliveira Salazar. Arquivo Nacional da Torre do Tombo, Arquivo Oliveira Salazar, AOS/CP-108, cx. 965, fl. 280v.

${ }^{5}$ Para Fernando Martins "é defensável argumentar que pode ter havido uma certa promiscuidade ou interdependência, entre aquilo que foi a ascensão de Pedro Theotónio Pereira à subsecretaria de Estado das Corporações e Previdência Social e o início do fim do movimento Nacional Sindicalista" (MARTINS, 2004b vol. I: 377).

${ }^{6}$ Num dos seus relatórios enviados a Salazar, o seu secretário particular, Tenente Assis Gonçalves afirmou, em fevereiro de 1932 que "A gente do N.S. poderá servir para alguma coisa (p. ex. - acção de organização social-corporações) [...]” (GONÇALVES 1981: 81).
} 
Militante nas fileiras da organização de carácter doutrinário denominado 'Nacional-Sindicalismo', pensei sempre, como pensa a grande maioria, a quási totalidade dos meus amigos políticos, que, sendo 'o NacionalSindicalismo', um movimento exclusivamente doutrinário, que aceitava o pensamento político, económico e social definido por V. Exa . no célebre discurso da Sala do Risco, cada um de nós estava bem, quando estivesse sob o comando directo de V. $\mathrm{Ex}^{\mathrm{a} 7}$.

Como se pode averiguar pela passagem transcrita, o gérmen do reconhecimento de Salazar como a figura conciliadora das direitas em Portugal já se encontrava instalado. É precisamente através do mencionado discurso da Sala do Risco, proferido em 1930, que se assiste à "primeira grande divisão de águas" em que "a Ditadura deveria conduzir ao advento de um novo regime político e social" (ROSAS, 2013: 34), conseguindo aplacar algumas dúvidas existentes nas forças em presença. Como se pode verificar, tais dúvidas ficaram suficientemente bem esclarecidas, ao ponto de potenciar a adesão de alguns à emergente fação salazarista.

A consumação da rutura de Castro Fernandes com o nacional-sindicalismo deuse após o I Congresso Nacional-Sindicalista, em novembro de 1933. A consolidação da sua posição no regime ficaria demonstrada pela sua participação, enquanto delegado, no I Congresso da UN, realizado em maio de 1934. Embora considerada como normal pelo próprio, esta nova filiação institucional não se resumiu a uma mera transição do movimento liderado por Rolão Preto para o regime que, pouco a pouco, se consolidava em Portugal. Indo ao encontro do principal foco temático deste artigo, era também o ideário corporativo que se mostrava atrativo para esta figura. Não poderemos considerar que a defesa de tal modelo se encontrava isolada nos movimentos doutrinários próximos de Salazar. O próprio Nacional-Sindicalismo defendeu a operacionalização de tal ideal, sendo as corporações a forma preferencial para estabelecer "a verdadeira Justiça Social," (TINOCO, 1933: 30) e o "Estado Nacional-Sindicalista impõe através da Corporação o respeito mútuo duns [dirigidos] e o cumprimento integral dos outros [dirigentes]" (PRETO, 1933: 28). Como veremos em seguida, Castro Fernandes seria

\footnotetext{
${ }^{7}$ FERNANDES, António Júlio de Castro (1933). Carta a António de Oliveira Salazar. Arquivo Nacional da Torre do Tombo, Arquivo Oliveira Salazar, AOS/CP-108, cx. 965, fl. 281.
} 
um destacado colaborador na criação da ossatura corporativa, tendo escrito várias obras que teorizavam e conceptualizavam tal doutrina.

A sua ação não se centraria nos corredores das instituições salazaristas ou em eventos públicos. A esfera pública e a imprensa foram igualmente alvo da sua atenção. Neste sentido, esteve envolvido na génese de algumas publicações de cariz doutrinário, ainda nos anos anteriores à sua entrada no seio do poder. É deste modo que, enquanto nacional-sindicalista, esteve presente na atividade do diário académico Revolução e chefiou a redação do jornal Revolução Nacional dos Trabalhadores. Com António Pedro, um “típico intelectual da «geração fascista» (PINTO, 1994: 105), fundaria uma editora chamada UP, da qual sairiam impressos vários folhetos e opúsculos de propaganda nacional-sindicalista. $\mathrm{O}$ interesse pelos meios culturais traduzir-se-ia noutras dimensões. Nos anos 70, Castro Fernandes lembrava que "em rapaz aderi sem restrições ao futurismo, criado por Marinetti, e que acompanhei com entusiasmo os movimentos artísticos e literários que apareceram entre nós" na "luta travada contra a incompreensão burguesa" (FERNANDES, 1972a: 9). Neste círculo intelectual de “jornalistas, homens de Letras, artistas plásticos, [de que] fizeram parte grandes amigos" (FERNANDES, 1971: IX) contavam-se ainda António Ferro, António Botto, Fernando Pessoa e Almada Negreiros ${ }^{8}$.

Posteriormente, com a consolidação do regime, a sua participação nos meios de comunicação permaneceu. Dirigiu o Boletim dos Organismos Patronais, publicação periódica que se centrava na divulgação dos propósitos e atividades dos organismos de coordenação económica. Outro desses casos ocorreu com o semanário Acção, publicado entre maio de 1936 e junho de $1937^{9}$. Neste periódico colaborariam figuras próximas de Castro Fernandes, como Abílio Pinto de Lemos, Luiz Forjaz Trigueiros e António Pedro. Nas suas próprias palavras, era pretendido fazer "um órgão de vanguarda, de tiragem muito grande, lido por uma massa de gente e não por uma coterie de

\footnotetext{
${ }^{8}$ Num texto de cariz memorialístico, Castro Fernandes relata o seguinte: "tive a alegria e a consolação de ser encarregado pelo Doutor Salazar de, em nome do Conselho Corporativo, perguntar ao José de Almada Negreiros se aceitaria representar os artistas plásticos na subsecção das Belas-Artes da Câmara Corporativa na IX legislatura. Não mais esquecerei que foi aqui em minha casa que o Almada respondeu, aceitando" (FERNANDES, 1971: XI).

${ }^{9}$ Este jornal seria financiado pelo governo. Como Theotónio Pereira referiu em carta a Salazar, em 15 de janeiro de 1937, "S. V. Ex . estivesse de acordo, a entrega da verba referente ao ano passado, far-se-ia agora por uma só vez. Seriam 50 contos e mais 5 por mês a começar no mês corrente e podendo fazer-se a entrega por via do Sub-Secretariado das Corporações e por reforço da verba de que este dispõe" (PEREIRA, 1981: 75).
} 
convertidos"10. Mostrava ainda ter "a ambição sincera de prestar um serviço à causa do Estado Novo, evitando que tenham que ser os próprios órgãos oficiais a fazer novas experiências ruinosas e sem sucesso positivo de difusão de ideais"11. Também na FNAT, seria um dos responsáveis pelas alterações no jornal oficial da instituição, $o 1^{o}$ de Maio, pedindo a suspensão temporária do mesmo, em 1942, alegando que "não tinha o alcance social que seria para desejar" (VALENTE, 1999: 80).

O seu contributo não esgotou nesta vertente, estando envolvido em outros momentos contributivos para a consolidação do regime fascista. Foi um dos oradores do comício anticomunista realizado no Campo Pequeno (Lisboa), em 28 de agosto de 1936, organizado pelos sindicatos nacionais e pela FNAT, resultando da "pressão de base correspondente aos desejos e aspirações da direita radical" (RODRIGUES, 1996: 36-37). Nesta ocasião, além do libelo acusatório sobre o marxismo, defendeu que "serse comunista é ser-se moscovitista, quere dizer, é ser-se contra a Pátria em que se nasceu” (FERNANDES, 1937: 83). Também demonstrou que a sua luta era travada para "defender a nossa liberdade e a nossa independência" e que "somos contra o comunismo porque somos portugueses" (FERNANDES, 1937: 85). Num tópico recorrente aos exercícios retórico-doutrinários do nacionalismo radical, o comunismo era encarado como elemento que, devido à sua almejada transnacionalidade revolucionária, colocava em perigo as independências dos países. Concludentemente, era necessário combatê-lo e, se possível, extirpar quaisquer elementos que pudessem ajudar na implantação de tais ideias na sociedade.

O corporativismo apresentava-se como forma para a erradicação do socialismo, mas também do liberalismo, ostentando uma plasticidade muito útil a um regime em consolidação. É neste campo de ideias que Castro Fernandes irá colher inspiração e que contribuirá para o aprofundamento da doutrina corporativa em Portugal, olhando para o caso da Itália fascista, nação tida como modelo. Seguidamente, será esse o tema em análise.

\section{“O imperativo da Idade Nova" e o paradigma italiano}

10 FERNANDES, António Júlio de Castro (1936). Carta a António de Oliveira Salazar. Arquivo Nacional da Torre do Tombo, Arquivo Oliveira Salazar, AOS/CP-108, cx. 965, fl. 283.

${ }^{11}$ FERNANDES, António Júlio de Castro (1936). Carta a António de Oliveira Salazar. Arquivo Nacional da Torre do Tombo, Arquivo Oliveira Salazar, AOS/CP-108, cx. 965, fl. 283. 
Estando plenamente integrado na ordem política vigente, Castro Fernandes tornar-se-ia um dos teorizadores do património doutrinário que a "escola corporativa" portuguesa se encarregou de elaborar, cujos postulados tiveram espaço de materialização depois de 1933, após a feitura da lei fundamental do Estado Novo, embora com vários matizes. Categoricamente afirmou que "à hora presente corresponde uma doutrina: o corporativismo" (FERNANDES, 1938: 18). O sistema corporativo foi uma parte elementar do projeto político do regime de Salazar, na medida em que funcionou como mecanismo de regulação económica e controlo social, presumindo-se que era uma alternativa "capaz de superar os sistemas dominantes do capitalismo liberal e o socialismo comunista" (GARRIDO, 2016: 133).

Dentro da primeira geração de doutrinadores, Castro Fernandes será o que mais se aproximará de uma clara sintonia com o modelo mussoliniano. Na sua obra $O$ corporativismo fascista, publicada em 1938, encontra-se um extenso relato da organização corporativa italiana, sendo em Portugal "o único estudo dos anos trinta sobre o corporativismo fascista" (SERAPIGLIA, 2006: 109). Constituindo um sumário do relatório apresentado ao Instituto para a Alta Cultura e ao Conselho Técnico Corporativo do Comércio e Indústria, a obra apresenta-se como "resultado dum estudo directo, constituído pela compilação de observações colhidas pessoalmente e apoiadas nos textos legais e na literatura especializada" (FERNANDES, 1938: 10). A maioria da obra ocupa-se de uma pormenorização da evolução da organização sindical; da inserção dos trabalhadores industriais, agrícolas e das profissões liberais; da assistência e previdência e da descrição das principais instituições políticas de Itália (Conselho Nacional das Corporações, Ministério das Corporações, Partido Nacional Fascista).

Castro Fernandes discorre também sobre os fundamentos teórico-doutrinários em que se baseia a organização corporativa. Aqui, alerta para o facto de ser algo em permanente construção. Se, enquanto experiência, "evolui: modificando-se, corrigindose, adaptando-se", já como doutrina "ainda não atingiu, também a sua fórmula decisiva e perfeita" (FERNANDES, 1938: 17). Surge outro fator que deveria ser realçado: a relação homem-Estado, interrogando-se se as "possantes rodagens do aparelho revolucionário italiano não esmagarão definitivamente o indivíduo, trucidando com bruteza a sua dignidade?" (FERNANDES, 1938: 27). Como resposta, apresenta-se a ideia de que o corporativismo fascista, baseado numa ideia individualista, preserva-se a essência da dignidade e o valor da pessoa. Mas este individualismo não é comparável 
aos conceitos do positivismo ou do racionalismo. O homo novus criado pela doutrina corporativa é concebido "num estudo integral e totalitário da realidade complexa que é o indivíduo" (FERNANDES, 1938: 31). Mais do que algo impositivo, a lição colhida é a de que através desta teoria é possível que o homem encontre, no Estado corporativo, a possibilidade de reconhecimento da sua poliédrica dimensão. É recuperado o homem real, nas suas múltiplas vertentes: política, económica, religiosa e social, assumindo-se como "o centro da vida e da História" (FERNANDES, 1938: 31).

A apologia feita à experiência italiana advém do facto de que, neste país, o corporativismo de associação ter sido conseguido, contrariamente, ao que se verificaria em Portugal, onde o corporativismo de Estado foi a operacionalização possível dos desígnios da doutrina. Castro Fernandes demostrou isto mesmo, tendo escrito que "sempre acreditei no corporativismo de associação" e que "à parte certos desvios de rota, a doutrina era adequada" (FERNANDES, 1972b: 31).

Atendendo aos particularismos expostos, é exequível defender que Castro Fernandes emerge como um exemplo dos fluxos transnacionais das ideias corporativas, e em particular, o caso italiano, eram encarados como centrais na emergência de uma nova ordem política. Nos anos 30, verificava-se um "fascínio internacional que envolveu grande parte da opinião pública em relação ao novo regime italiano, que se apresentou como um reino de paz social e harmonia entre classes" (SANTOMASSIMO, 2006: 11).

\section{O enquadramento das atividades laborais}

Para alguns, a obtenção da modernidade política é conseguida enquanto um projeto de disciplina social e saberes normativos que geram códigos gerais de conduta que se apresentam como universais, impondo noções geométricas da realidade. $\mathrm{O}$ corporativismo recupera uma ordem social passada, modo a obter uma tranquilidade social efetiva. Igualmente, a modernidade encara a realidade como algo que pode ser manipulado, de forma planeada, e em que o Estado é produto e produtor desse objetivo. $\mathrm{O}$ trabalho e os trabalhadores portugueses seriam um dos focos que o regime se mostrou disposto a manipular, sob o desígnio da ordem e uma certa ideia de modernidade. 
Para Castro Fernandes, em primeiro lugar, "[...] uma característica da sociedade moderna é a organização e portanto a ordem. Ordem nas coisas, ordem nas ideias, ordem na vida de cada dia" (FERNANDES, 1938: 199). Seria através desta modalidade teórica corporativa, na qual estaria contida uma dose de modernidade, que os conflitos sociais cessariam, ou seja, “[...] a morte do Estado liberal e o advento do Estado corporativo fez perder à luta de classes aquele carácter social que teve quando se manifestaram os primeiros movimentos de massas" (FERNANDES, 1938: 201). Também as lutas entre patrões e operários, além de consideradas episódicas, mas normais, seriam facilmente controláveis. Esse controlo era conseguido através de uma organização paralela dos interesses, isto é, “[...] organismos diferenciados [que] actuarão no sentido da cooperação harmónica", moldando os espíritos dos seus membros partindo do "espírito cristão da paz social” (FERNANDES, 1944a: 38).

O trabalho revestia-se de uma dimensão despojada do materialismo capitalista e da obtenção pura do lucro para dar lugar a " [...] uma força criadora da vontade humana, com fim que o transcende, adquire um profundo sentido ético, social e económico" (FERNANDES, 1944b: 41). Esta atribuição de significados ao campo laboral encontrava, na solução corporativa, a sua forma mais habilitada de promover a simbiose entre interesses individuais e coletivos, dispondo de um conjunto de instituições promotoras desse desígnio. O que se concretizaria com o Estado corporativo era que, “[...] contra um sindicalismo fomentador dos mais baixos instintos das massas operárias embrutecidos pela miséria, o corporativismo proclamou a necessidade dos trabalhadores a um nível superior" (FERNANDES, 1944b: 52-53). Castro Fernandes notava que, no caso do regime nazi, a Deutsche Arbeitsfront tratava-se de uma "verdadeira emanação eficiente do Partido - tem uma actividade múltipla que atinge todos os aspectos e todos os campos" conseguindo "dar aos dirigentes e às massas uma consciência do pensamento oficial"12, algo dificilmente comparável à situação portuguesa.

Num discurso pronunciado em agosto de 1945, o então Subsecretário de Estado das Corporações, cargo que ocupava desde $1944^{13}$, clarificou os alcances da política social do regime português. Surgia como preocupação principal "aumentarmos a

\footnotetext{
${ }^{12}$ FERNANDES, António Júlio de Castro (1938). Carta a António de Oliveira Salazar. Arquivo Nacional da Torre do Tombo, Arquivo Oliveira Salazar, AOS/CP-108, cx. 965, fl. 286.

${ }^{13}$ Tal nomeação inscreve-se na remodelação ministerial conduzida em setembro de 1944. Seguindo as memórias de Marcello Caetano, tal facto decorreu da necessidade de Salazar de "tão só rodear-se de pessoas seguras, na maior parte provadas na sua dedicação ao Regime e ao seu chefe" num tempo em que se dizia que "aquele governo ia ter muitas dificuldades, ia ser talvez o último do Estado Novo" (CAETANO, 1977: 7).
} 
riqueza ou retificarmos a distribuição dos benefícios sociais de que ela é portadora" (FERNANDES, 1945: 15). Por outro lado, era pretendido alterar as mentalidades, contrapondo cultura de classe à cultura popular e individualismo ao interesse nacional. $\mathrm{Na}$ formulação deste postulado dicotómico surgia a pretensão da "emancipação espiritual dos trabalhadores que nós queremos firmemente que participem no património da Civilização" (FERNANDES, 1945: 15). A convocação das classes trabalhadoras colhia, na sua visão, exemplos notórios que justificariam a sua satisfação para com a obra do Estado Novo. Neste campo, "não nos poderemos considerar distanciados pelas nações mais progressivas e mais interessadas em resolver a chamada questão social" (FERNANDES, 1945: 7). As várias leis promulgadas sobre a atividade laboral eram sintoma de como o exercício do poder não colocava à margem os anseios dos trabalhadores.

Neste campo, poderemos incluir as questões relacionadas com a previdência corporativa, quer no âmbito salarial, quer no campo da proteção conferida no trabalho, com os contratos coletivos de trabalho. Logo nos primeiros anos do Estado Novo e em resposta aos críticos, Castro Fernandes advogava a importância do modelo corporativo. Tal facto residia na seguinte questão: era "mais justo, mais digno, mais sério e mais honesto que o salário e horário de trabalho sejam determinados por patrões e pelos empregados" (FERNANDES, 1934: 12).

Como elemento fundamental na relação entre trabalhadores e patronato surgiam os contratos coletivos de trabalho. Com estes, era possível, não apenas desmentir "o errado e criminoso princípio marxista da luta de classes", mas também, realizar as "mais justas e mais compreensíveis aspirações” no domínio laboral (FERNANDES, 1937: 38). Uma vez mais, o combate contra o ideário de esquerda era algo basilar para este economista.

\section{Realidades quotidianas discursadas: lazer e previdência}

Mas não eram apenas as relações no plano laboral que a Castro Fernandes interessavam. Igualmente a ocupação dos tempos livres dos trabalhadores, tópico a que 
o Estado Novo devotou a sua atenção ${ }^{14}$ e que encontrou no pensamento desta figura espaço de reflexão. Em primeiro lugar, foi um dos mais estreitos colaboradores na génese da FNAT, estando presente nos primeiros passos desta instituição. Dada a experiência adquirida como vogal da Comissão Central (1935-1940) e vice-presidente da Direção da FNAT (1941-1944) não terá sido estranho que este tópico fosse caro a Castro Fernandes. Além disso, foi membro da delegação portuguesa e vice-presidente da Comissão Organizadora do Congresso Mundial Trabalho e Alegria de Roma, realizado em 1938.

Surgia a pertinência de arregimentar e controlar as atividades lúdicas e de recreio das massas trabalhadoras, existindo "a imperativa associação indissolúvel do homo faber e do homo ludens a qual não consente que o recreio, o jogo, se separe da cultura"15. A organização das horas livres assume a sua pertinência pois "não se trata de criar obrigações novas para cada indivíduo. Trata-se de permitir que cada trabalhador tire, dos vagares que lhe dá uma vida profissional menos absorvente, as vantagens de que ele próprio beneficiará e de que aproveitará toda a colectividade" (FERNANDES, 1943: 13). Os proventos retirados da implementação de um esquema para o descanso não se tratava apenas do cumprimento de um objetivo individualista, tendo reflexos na própria inserção do trabalhador na comunidade. O aproveitamento dos tempos livres dos trabalhadores tratava-se de "um verdadeiro problema, uma obra nacional, e como todos os problemas necessita de ser resolvido, tem que ser resolvido e há-de sê-lo pela Organização Corporativa"16.

Um dos aspetos trabalhados por Castro Fernandes seria a constituição de bibliotecas no seio dos Sindicatos Nacionais ${ }^{17}$, sendo uma forma de educação popular. Também nas Casas do Povo esta seria uma realidade. Num esforço de "reagir contra a dissolução da língua portuguesa que se está verificando nos meios urbanos" ${ }^{\text {18, }}$, era necessário que as populações rurais estivessem munidas de "livros redigidos num estilo

\footnotetext{
${ }^{14}$ É de referir que a ação do Secretariado de Propaganda Nacional, encetada por António Ferro, apresenta uma retórica similar à da FNAT. Como traço de união às duas instituições estava a reprodução da ideologia, sendo órgãos centrais de propaganda do regime, mas os seus cruzamentos e sobreposições de atividades distinguiam-se nos objetivos fundamentais de cada uma. Se o SPN focava a elaboração de uma política folclorista e a encenação de um conjunto de práticas artísticas e culturais, já a FNAT centrava a sua missão no controlo dos tempos livres dos operários. Para além do mais, havia, por parte dos dirigentes da FNAT nos seus primeiros anos, a reivindicação de um estatuto especial para a realização destas atividades, numa ideia centralizadora e totalizante do domínio da ação propagandística.

${ }^{15}$ Alegria no Trabalho, ano III, $\mathrm{n}^{\circ} 30$, junho de 1947, p. 149.

${ }^{16}$ Alegria no Trabalho, ano I, $\mathrm{n}^{\circ}$ 7, julho de 1945, p. 104.

$171^{o}$ de Maio, $2^{\mathrm{a}}$ série, $\mathrm{n}^{\mathrm{o}} 2,10$ de maio de 1941, p. 6.

${ }^{18}$ Alegria no Trabalho, ano I, no 6, junho de 1945, p. 79.
} 
que se preste à leitura em voz alta ${ }^{19}$ durante os serões das Casas do Povo" ${ }^{20}$. Outras das formas de propaganda ideológica encontradas foi o uso dos meios radiofónicos. Em colaboração com a Emissora Nacional, foi criado o programa Meia Hora de Cultura Popular, tendo Castro Fernandes um papel ativo nesta iniciativa, embora com alcance menor do que o pretendido.

Sobre a questão do desporto e da educação física, também se encontram alguns contributos conceptuais. Desde logo, a definição de educação física era, para a figura em estudo, suficientemente ampla, de modo a abarcar, não apenas as atividades desportivas, mas também as questões da profilaxia e a higiene e, neste sentido, a colaboração com a Assistência Nacional aos Tuberculosos era desejável. Neste modelo e no que às cidades é respeitante, lugares onde a prática de alguns desportos já estava enraizada, como era o caso do futebol, para o meio rural seria necessário outras abordagens. Em primeiro lugar, e convocando a atuação das Casas do Povo, seria necessário "estudar a estilização ginástica e desportiva, tanto dos exercícios físicos tradicionais do povo português como dos jogos de crianças e adolescentes, utilizados como meio de ensino". Se o desporto praticado em meio urbano apresentava uma "tendência cada vez mais internacional, existiria também o desporto campestre, mais típico e nacional, portanto mais artístico" ${ }^{21}$. Tal como era apanágio da política cultural salazarista, o reencontro com uma pureza identitária remanescente nas áreas rurais era um noção que era necessário precisá-la por contraste às vivências urbanas, usando para isso variados mecanismos. Para Castro Fernandes, da leitura ao desporto, existiam várias baluartes em que assentava esta intenção.

Embora o salazarismo tenha dado alguns passos, "cujo programa constitui por si só um índice da nossa política de reconhecimento da dignidade do trabalho" (FERNANDES, 1945: 14), nos anos 40, esta ideia adquiriu novos particularismos. Colhendo os exemplos conseguidos pelos outros regimes fascistas, Castro Fernandes considerava que, na experiência portuguesa, era necessária a responsabilidade na “valorização humana do trabalhador” (FERNANDES, 1943: 26). Mas será uma vez mais o exemplo italiano o que é considerado como o mais bem conseguido, "animado

\footnotetext{
${ }^{19}$ As sessões de leitura nas Casas do Povo teriam um regulamento próprio, publicado em 5 de julho de 1946 (Boletim do Instituto Nacional do Trabalho e Previdência, ano XIII, nº 13, 15 de julho de 1946, p. 307).

${ }^{20}$ Alegria no Trabalho, ano I, $\mathrm{n}^{\circ}$ 6, junho de 1945, p. 79.

${ }^{21}$ Boletim do Instituto Nacional do Trabalho e Previdência, ano XII, no 4, 28 de fevereiro de 1945, p. 108.
} 
dum espírito inteiramente novo e revolucionário" (FERNANDES, 1947: 24) através do Dopolavoro. É neste espírito que, enquanto membro do governo, em 1945, procedeu à reformulação das competências e das estruturas da FNAT, uma instituição marcada pela "vasta versatilidade de iniciativas que abarcaram por igual os grandes e pequenos centros" (PEREIRA, 1972 vol. I: 190). Para a prática desportiva e a organização de espetáculos e divertimentos, era vital que a "FNAT aperfeiçoe cada vez mais estes serviços e que possa vir a ser dotada com os meios necessários para exercer com eficiência a sua acção coordenadora e estimuladora"22.

No seio da posição do Estado face aos trabalhadores em matéria de previdência, encontra-se uma permanente atenção de Castro Fernandes às novidades trazidas pelo Relatório Beveridge que, em 1942, lançou as bases do Estado Social em Inglaterra. Considerando que este foi "uma grande tentativa de organização da segurança social na mais larga extensão do conceito que ela admite" (FERNANDES, 1947: 36), a universalização dos cuidados assistenciais feita pelas democracias encerrava os seus perigos. É desta forma que encontramos a defesa do modelo usado em Itália, isto é, “da espiritualidade corporativa face ao paganismo do padrão-de-vida do Welfare State" (VALENTE, 1999: 125). Esta preocupação traduziu-se em algumas reflexões suas. Com o fim da guerra, em 1945, referiu que era "o momento oportuno para definir a tendência no sentido da integração progressiva do "abono de família", na mecânica das Caixas de Previdência"23. Como o próprio reconheceu, "com o termo das hostilidades, transitou para o primeiro plano a preocupação do social", não estando os políticos portugueses "distanciados por este movimento geral dos espíritos" 24 .

Esta terá sido uma das razões que, em contexto de crise económica no rescaldo da Segunda Guerra Mundial, Castro Fernandes procedeu à revisão dos salários de vários grupos profissionais, como na indústria das conservas ou no dos empregados bancários. Como o próprio relatou, estes aumentos “apesar de tão imperiosamente necessários, não podiam deixar de estimular em todos os sectores, por simples efeitos de capilaridade, a reivindicação de ordenados ou salários mais altos", atestando "carácter isolado das minhas intervenções" 25 .

\footnotetext{
${ }^{22}$ Alegria no Trabalho, ano III, $\mathrm{n}^{\circ}$ 34, outubro de 1947, p. 273.

${ }^{23}$ FERNANDES, António Júlio de Castro (1945). Carta a António de Oliveira Salazar. Arquivo Nacional da Torre do Tombo, Arquivo Oliveira Salazar, AOS/CP-108, cx. 965, fl. 288.

${ }^{24}$ Alegria no Trabalho, ano I, $\mathrm{n}^{\circ}$ 9, setembro de 1945, p. 161.

${ }^{25}$ FERNANDES, António Júlio de Castro (1947). Carta a António de Oliveira Salazar. Arquivo Nacional da Torre do Tombo, Arquivo Oliveira Salazar, AOS/CP-108, cx. 965, fl. 293.
} 
Apesar do tom laudatório, próprio de um elemento envolvido nos trâmites da construção do corporativismo, a dimensão da previdência baseou-se, ao longo do Estado Novo, "na responsabilidade do assistido e da família, no imperativo de formação moral e no dever do trabalho", permanecendo "o carácter supletivo do Estado em relação à sociedade civil, e a natureza categorial, complementar e emergencial da assistência" (BRANCO, 2017: 539).

\section{A constelação corporativa}

O Estado corporativo e o cumprimento do seu curso histórico foram conseguidos com uma "uma rede de organizações paraestatais, fortemente hierarquizada e ligada ao centro de decisão política do Estado Novo através de vários órgãos" (FREIRE, FERREIRA, 2017: 158), o que comportava uma imposição e expropriação de poderes. Foram variáveis os mecanismos de intermediação política e institucional, mas o corte com a cultura liberal e os princípios de representação política e laboral foi claro. A reordenação do espaço social levou a que fosse a relação entre o capital e o trabalho fosse garantida através de um conjunto de agrupamentos que pontilhavam o país: Grémios, Sindicatos Nacionais, Casas do Povo e Casas dos Pescadores, “organismos capazes de prevenir movimentos de ação coletiva conotados com a pregação marxista da luta de classes" (GARRIDO, 2016: 95). Estes tinham, entre variadas funções, a representação das classes profissionais, funcionando como plataforma de mediação e o "supremo garante da «disciplina social»" (ROSAS, 2019: 176).

Neste aspeto, Castro Fernandes alertou para uma das especificidades do corporativismo português: o princípio da especialização orgânica. De acordo com este postulado, contrariamente a qualquer ideia de geometrização das atividades profissionais, a cada ramo ou classe laboral correspondia, de forma natural, um grémio ou sindicato nacional. Esta seria, na sua opinião, a "completa originalidade da organização corporativa portuguesa” (FERNANDES, 1944a: 42). A sua teorização pretendia ainda marcar "a diferença que existe entre o sindicalismo vermelho e o sindicalismo corporativo" 26 . Algumas mudanças e estratégias, porém, teriam de ser

\footnotetext{
${ }^{26}$ Alegria no Trabalho, ano III, no 41, maio de 1948, pp. 92-93.
} 
tomadas quando se transplantava estas noções para o meio rural, condicionando a sua perspetiva sobre a aplicação do modelo corporativo nestas regiões.

As Casas do Povo eram "o centro de convivência da gente rural, o seu lar colectivo, seu instrumento de representação, seu núcleo polarizador de iniciativas do interesse geral" (FERNANDES, 1947: 23), constituindo a "Verdadeira Casa, lar do trabalhador do campo" (FERNANDES, 1944b: 59). A defesa do mundo rural encontra, numa das medidas tomadas na Subsecretaria de Estado da Corporações, um elemento importante: a criação da Junta Central das Casas do Povo (JCCP), em janeiro de 1945, sendo a Comissão Executiva presidida pelo próprio Subsecretário de Estado $^{27}$. Quando deu posse à JCCP, Castro Fernandes enunciou uma série de preceitos que deveriam conduzir, não apenas a ação deste organismo, mas também a política corporativa para os meios rurais. Desta sua intervenção, sobressai um entendimento comum a outros intelectuais do regime sobre a valorização da vida rural como elemento identitário e que salvaguardava a essência nacional. Em oposição aos meios industrializados, conducentes a uma descaracterização da ambiência social, "é a vida rural que realiza, em cada povo, a percentagem máxima do particular, a mais proporção do nacional", excluindo, "por via de regra, as profundas diferenciações de classes" 28 . As comunidades rurais guardariam uma comunhão dos mesmos valores, ideias e costumes, para a qual contribuía um profundo contacto com a terra, aceitando "a lei dura das limitações"29. O reconhecimento desta aura mediocritas levava a que as Casas do Povo mais não fossem do que "a expressão do núcleo humano da freguesia rural, cujos elementos atómicos são inseparáveis" $" 30$.

Atendendo a esta especificidade, não poderia haver, segundo Castro Fernandes, algum tipo de comparação com os Sindicatos Nacionais ou os Grémios do Comércio e Indústria. Isto é, se nestes organismos o que se encontrava era a representação de classes e profissões diferenciadas e nos Grémios da Lavoura era a elite patronal que constituía a massa associativa, nas Casas do Povo não era possível fazer representar um ou outro interesse particular porque a solidariedade existente nos campos limitava as intenções unificadoras das gentes. Como sintetizou, "a fórmula que se escolheu é, pois, aquela que mais fielmente se adapta a uma realidade que não temos o direito de

\footnotetext{
27 Boletim do Instituto Nacional do Trabalho e Previdência, ano XII, no 4, 28 de fevereiro de 1945, pp. 99-109.

${ }^{28}$ Alegria no Trabalho, ano I, no 3, março de 1945, p. 28.

${ }^{29}$ Alegria no Trabalho, ano I, no 3, março de 1945, p. 29.

${ }^{30}$ Alegria no Trabalho, ano I, no 3, março de 1945, p. 29.
} 
ignorar"31. As Casas do Povo teriam ainda de superar uma lógica burocrática e administrativa, para se converterem em elementos dinâmicos e não em puros organismos de classe, obra essa para a qual estavam convocados vários elementos sociais. Nesta coordenação de esforços, estaria baseado o êxito da ação da previdência e da assistência social e o esforço da instrução dos populares.

Também as Casas dos Pescadores eram apresentadas como organismos habilitados a superar "o risco da injusta miséria e do desamparo em que o lançavam a ele [pescador] e à família as tradições do mar e o imprevisto da sorte" ${ }^{\text {32 }}$. Ao ambiente de colaboração em matéria laboral que estas proporcionavam, aliava-se a ação social, na qual se incluía os postos de puericultura, creches, asilos, internatos, os lares dos pescadores e o serviço de visitadoras. Tudo isto desembocava na constatação de que era uma obra que "quebra a barreira do isolamento moral em que o trabalhador vivia" 33 .

\section{"Não temos que rever nem que emendar": a afirmação da infalibilidade do corporativismo na fase final do regime}

Abandonando a pasta das Corporações, Castro Fernandes toma posse como Ministro da Economia, a 16 de outubro de 1948, sucedendo a Daniel Barbosa. No período em que ocupou tais funções sobressai uma política económica de teor mais conservador do que o seu antecessor. Porém, o progressivo processo de abertura económica ao exterior constituiu uma realidade inelutável, consumada nas décadas seguintes. Ainda assim, a preservação da boa imagem da organização corporativa permaneceu. Atente-se nas diligências tomadas junto de Marcello Caetano, em 1949, para que, perante as informações tendentes a acusar o Grémio dos Armazenistas de Vinho de especulação e manipulação de preços, fosse publicado num jornal, informação que mostrasse o contrário. "Pode você promover a sua publicação? Parece-me errado fazê-la como nota oficiosa do Ministério [...] Se a nota do G. dos A. de Vinhos e a entrevista do C. Mendonça vierem publicadas, responde-se cabalmente ao folheto no q[ue] se refere à org. corporativa" 34 , referiu Castro Fernandes numa carta a Caetano.

\footnotetext{
${ }^{31}$ Alegria no Trabalho, ano I, no 4, abril de 1945, p. 46.

32 Boletim do Instituto Nacional do Trabalho e Previdência, ano XII, nº 9, 15 de maio de 1945, p. 289.

33 Boletim do Instituto Nacional do Trabalho e Previdência, ano XII, nº 9, 15 de maio de 1945, p. 289.

34 FERNANDES, António Júlio de Castro (1949). Carta a Marcello Caetano. Arquivo Nacional da Torre do Tombo, Arquivo Marcello Caetano, Correspondência, cx. 26, nº 2, fl. 1.
} 
Com o término da sua passagem pela tutela da Economia, a 2 de agosto de 1950, torna-se administrador do Banco Nacional Ultramarino, conciliando a sua atividade na banca com a política. Esta entrada no meio bancário foi feita, segundo o próprio, com "profundo sentimento de gratidão" e "quando neste momento dissesse, além de «muito obrigado», seria certamente perturbado e inexpressivo"35. Será na presidência da Comissão Executiva da UN, nos anos finais do governo de Salazar, que Castro Fernandes encontrará o seu principal campo de atuação política. Ao ser convidado para assumir o cargo, em outubro de 1958, escreveu a Salazar que "as ordens de Vossa Excelência cumprem-se, sobretudo sabendo-se, como se sabe, q[ue] a tarefa não é fácil nem cómoda" 36 . Apesar da fidelidade ao ditador, mostrou as suas reservas sobre a saída de Marcello Caetano do governo, nesse mesmo ano. Nas suas palavras, "Somos tradicionalmente extravagantes no sentido de esbanjadores e desgovernados. Só essa ancestral fatalidade pode explicar q[ue], neste nosso paupérrimo mercado de valores, se dispense a colaboração de um insubstituível valor" ${ }^{37}$. Do ponto de vista profissional, seria nos anos 60 que ocuparia, novamente, um cargo num organismo corporativo, desta vez como presidente da direção do Grémio Nacional dos Bancos e Casas Bancárias (1963-1972) sendo, por inerência, vogal da comissão revisora de contas da Fundação Gulbenkian.

Não obstante as funções ocupadas na fase final do regime, cujo desempenho, forçosamente, levava à discussão de outras problemáticas, a infalibilidade do corporativismo ainda permaneceria como ponto cardeal do seu pensamento político. À época urgia definir e deslindar algumas questões que permaneciam com respostas difusas. Num discurso proferido na sede da UN, a 15 de fevereiro de 1960, no que se referia ao estado do corporativismo português, "no exame das relações entre a Organização Corporativa e a ossatura política na Nação, haverá que ventilar as influências mútuas dos blocos e os casos de interpenetração" (FERNANDES, 1960: 11). Nesta questão, era pretendido perceber até que ponto ocorria a interferência do corporativismo nas formas de intervenção política, nomeadamente, os vários

35 FERNANDES, António Júlio de Castro (1950). Carta a António de Oliveira Salazar. Arquivo Nacional da Torre do Tombo, Arquivo Oliveira Salazar, CP-108, cx. 965, fl. 311.

${ }^{36}$ FERNANDES, António Júlio de Castro (1958). Carta a António de Oliveira Salazar. Arquivo Nacional da Torre do Tombo, Arquivo Oliveira Salazar, CP-108, cx. 965, fl. 314.

37 FERNANDES, António Júlio de Castro (1958). Carta a Marcello Caetano. Arquivo Nacional da Torre do Tombo, Arquivo Marcello Caetano, Correspondência, cx. 26, nº 5, fl. 1. 
departamentos do Estado e se era possível encontrar uma verdadeira representação classista e de defesa dos interesses nas estruturas coevas.

Outras das questões levantadas inscrevia-se na compreensão da gestão dos interesses entre trabalhadores e patrões. Por outras palavras, "o Corporativismo, como nós o entendemos, suprime ou não a luta de classes?” (FERNANDES, 1960: 12). Ainda no plano social e económico, Castro Fernandes questionava qual o verdadeiro sentido da direção corporativa da economia e "se efectivamente existe uma economia corporativa, qual é o seu espírito e qual o seu grau de autonomia?" (FERNANDES, 1960: 12).

Este elenco de perguntas constituíram o mote para uma série de conferências realizadas em 1960, nas quais participariam Pedro Soares Martinez, Diogo Pacheco de Amorim, José Pereira Pinto, João da Cruz Lopes e Albano Dias de Magalhães. Através desta iniciativa, mas também pelo questionamento programático proposto por Fernandes, poderemos ver que o esforço de revitalização do pensamento corporativo tornou-se uma das diretrizes da UN, tentando debater os seus limites e possibilidades futuras.

Com os desafios impostos pelo início da guerra na África portuguesa, em 1961, e, consequentemente, pelo escrutínio internacional e progressivo isolamento do regime português, Castro Fernandes seria um dos elementos que poderíamos colocar na corrente conservadora dentro da ditadura. Na articulação destes vetores, manteve a fidelidade ao regime e, sobretudo, a Salazar. Segundo a sua visão, esta era uma figura que "tudo tem sacrificado ao devotado serviço da Pátria cuja sobrevivência depende do querer prodigioso de Vossa Excelência"38, assumindo a sua qualidade de "modestíssimo colaborador de Vossa Excelência q[ue] fui e como seu dedicadíssimo amigo"39.

A exoneração de Salazar, "o momento que desencadearia a tragédia testamentária" ${ }^{40}$ e que abriu caminhos para uma incerteza política ${ }^{41}$, conduziu Marcello

\footnotetext{
38 FERNANDES, António Júlio de Castro (1961). Telegrama a António de Oliveira Salazar. Arquivo Nacional da Torre do Tombo, Arquivo Oliveira Salazar, CP-108, cx. 965, fl. 342.

${ }^{39}$ FERNANDES, António Júlio de Castro (1961). Carta a António de Oliveira Salazar. Arquivo Nacional da Torre do Tombo, Arquivo Oliveira Salazar, CP-108, cx. 965, fl. 347.

${ }^{40}$ FERNANDES, António Júlio de Castro (1971). Carta a Marcello Caetano. Arquivo Nacional da Torre do Tombo, Arquivo Marcello Caetano, Correspondência, cx. 26, nº 9, fl. 2.

41 Numa das missivas enviadas a Caetano, Castro Fernandes relata uma curiosa situação, ocorrida em setembro de 1968, aquando dos eventos sobre a sucessão de Salazar: "Lembro-me q[ue], em determinada altura, alguém me entregou uma pistola e, ao ensinar-me o manejo da arma, comentou: «Tenha sempre a bala na câmara, porque nestes casos só se dá um tiro, o outro recebe-se...». (FERNANDES, António Júlio de Castro (1971). Carta a Marcello Caetano. Arquivo Nacional da Torre do Tombo, Arquivo Marcello Caetano, Correspondência, cx. 26, nº 9, fls. 2-3).
} 
Caetano à Presidência do Conselho de Ministros, em setembro de 1968. Seguidamente deram-se mudanças nas várias estruturas do regime e a que UN não escaparia. A 3 de dezembro, durante a reunião da Comissão Central, Castro Fernandes entendendo não ser desejável que se dessem mudanças de comando que poderiam perigar uma certa solução de continuidade, apresentou a sua demissão e, a 9 de dezembro, foi rendido por Guilherme Melo e Castro, uma escolha feita "para a dinamização da organização, num altura em que era vista como um mono político ${ }^{42}$ " (REIS, 2013: 88). Tal situação não terá provocado qualquer desentendimento entre as duas figuras. Em vários momentos, Castro Fernandes mostrou o seu apoio a Caetano, considerando como "um amigo q[ue] sempre lutou lado a lado, desde os recuados tempos da Federação Académica"43.

Ao longo do marcelismo, Castro Fernandes continuaria como procurador à Câmara Corporativa declarando, em 1973, o "muito honrado convite [d]o Conselho Corporativo para ocupar" tal lugar, que "aceito desvanecidamente" 44 . Apesar da sua permanência no circuito parlamentar, dedicar-se-ia, em exclusivo, à atividade bancária. Disso mesmo dá conta a ausência de intervenções no plenário neste período. O fim do regime, a 25 de abril de 1974, levou ao término da sua carreira política, vindo a falecer, em 1975.

\section{Conclusões}

Aqui chegados e de forma a concluir, importa perceber qual o protagonismo desempenhado por António Júlio de Castro Fernandes no seio da primeira geração de doutrinadores corporativistas, na qual podemos incluir os já mencionados Pedro Theotónio Pereira, João Pinto da Costa Leite e Marcello Caetano, além de Joaquim Teixeira Ribeiro e Mário de Figueiredo. Qual o seu lugar na "escola corporativa" portuguesa? Os elementos teóricos já mencionados permitem-nos elencar alguns tópicos

\footnotetext{
42 A inércia da UN já há muito que era notada. Numa audiência concedida por Oliveira Salazar, em 1959, Costa Brochado afirmou que "[a UN] vai mal, senhor Presidente, muito mal mesmo! [...] O Dr. Castro Fernandes não está lá por convicção mas apenas por consideração e gratidão por V. Ex. a . Não chega! É preciso esclarecer o País e realizar o Estado Novo, sem o que nada mais faremos" (BROCHADO 1987: 339)

${ }^{43}$ FERNANDES, António Júlio de Castro (1969). Carta enviada a Marcello Caetano. Arquivo Nacional da Torre do Tombo, Arquivo Marcello Caetano, Correspondência, cx. 26, nº 7, fl. 2.

${ }^{44}$ FERNANDES, António Júlio de Castro (1973). Cartão enviado a Marcello Caetano. Arquivo Nacional da Torre do Tombo, Arquivo Marcello Caetano, Correspondência, cx. 26, no 5, fls. 1-2.
} 
conclusivos, elaborando uma resenha final sobre as principais marcas patentes no discurso da figura analisada. Como fatores distintivos do pensamento corporativo deste economista, salientaríamos, principalmente dois. O primeiro é a importância conferida ao modelo italiano, tendo dedicado exclusivamente uma obra ao tema, atendendo ao facto de ser em Itália que o corporativismo de associação se materializara; o segundo foi a importância da doutrinação através do lazer, através de uma miríade de instrumentos e ações de propaganda.

Castro Fernandes desenvolveu uma teorização sobre os principais tópicos necessários à estruturação de um verdadeiro Estado corporativo. A sua produção escrita e a atuação pública levou-o a conceber a doutrina como forma de expiação dos defeitos dos regimes políticos anteriores, reatando os laços com um modelo de organização social perdido no largo período liberal. O corporativismo seria a forma ideal de arrumação, não apenas da economia, mas, sobretudo, das interações sociais, para as quais o contributo das instituições era inegável.

Se os outros doutrinadores devotaram maior parte da sua atenção aos arranjos económicos e jurídicos do corporativismo, suscitados pela oportunidade histórica conferida pelo Estado Novo, Castro Fernandes refletiu sobre matérias igualmente centrais. Um aspeto relevante no seu ideal de corporativismo foi a alusão, em vários momentos, sobre o papel desta doutrina no enformar de novas práticas quotidianas e lúdicas, sempre assente na sujeição a um controlo ideológico imposto pelo Estado. As bibliotecas, a rádio ou o teatro constituíam as peças que, pouco a pouco, iriam construir um edifício cujas fundações teriam de estar assentes no soberano princípio da harmonia classista. Era desta forma que as atividades de recreio proporcionadas pela FNAT ou pelas Casas do Povo deveriam estar enquadradas.

Uma menção aprofundada deve ser feita em relação às fontes manuscritas utilizadas. O que surge regularmente nas cartas tratadas é uma visão de clara sintonia com o regime, independentemente da conjuntura de redação, além de um reconhecimento tácito e concordante com a ordem vigente. Neste caso, o estatuto da escrita de si estabelece a materialização de uma identidade que pretende consolidar aos olhos dos principais dirigentes do Estado Novo.

O presente trabalho teve a preocupação de integrar António Júlio de Castro Fernandes, a sua doutrina e a sua prática, no contexto português, tendo em conta os movimentos de ideias que caracterizavam o seu tempo. Através desta personagem, foi possível compreender, de forma mais tangível, como os discursos são reveladores dos 
espaços de ação política. A articulação da crítica da política liberal com o projeto de um novo "mundo", sob a égide do corporativismo, passou obrigatoriamente, na figura em estudo, por um outro exercício do poder, pugnando por uma nova virtude na quotidianidade pessoal e coletiva.

\section{Fontes}

\section{Correspondências}

Arquivo Nacional da Torre do Tombo, Arquivo Oliveira Salazar, AOS/CP-108, cx. 965, f. $280-446$.

Arquivo Nacional da Torre do Tombo, Arquivo Marcello Caetano, cx. 26, Correspondência/FERNANDES, António Júlio de Castro, nº 1- nº 10.

\section{Fontes impressas: publicações oficiais e periódicos}

$1^{\circ}$ de Maio.

Alegria no Trabalho.

Boletim do Instituto Nacional do Trabalho e Previdência.

\section{Fontes impressas: discursos, estudos e memórias}

BROCHADO, Costa (1987). Memórias de Costa Brochado. Lisboa: Edição do Autor.

CAETANO, Marcello (1977). Minhas memórias de Salazar. Lisboa: Verbo.

FERNANDES, António Júlio de Castro (1934). Patronato e sindicatos nacionais.

Lisboa: Edições SOS.

(1937). Algumas palavras. Lisboa: Editorial Império.

(1938). O corporativismo fascista. Lisboa

(1943). A organização das horas livres. Lisboa: Fundação GAM.

- (1944a). Princípios fundamentais da organização corporativa portuguesa.

Lisboa: Editorial Império.

. (1944b). Temas corporativos. Lisboa: Edições SPN.

- (1945). A revolução social portuguesa. Lisboa: Secretariado Nacional de Informação.

(1947). A segurança dos trabalhadores através do seguro social. Lisboa:

Subsecretariado de Estado das Corporações e Previdência Social.

. (1960). Conferência da sede da UN. Sulco: revista de cultura político-social, $1^{\mathrm{a}}$ série, $\mathrm{n}^{\circ}$ 1, pp. 5-15.

. (1971). Três ciprestes. Lisboa: Tipografia Duarte.

. (1972a). Arquivo. Lisboa: Banco Nacional Ultramarino.

. (1972b). Corporativismo de associação. Lisboa: Grémio dos Bancos e Casas Bancárias.

GONÇALVES, Assis (1981). Relatórios para Oliveira Salazar: 1931-1939. Lisboa: Presidência do Conselho de Ministros/Comissão do Livro Negro sobre o Regime Fascista.

MUSSOLINI, Benito (1933). Le fascisme: doctrine, institutions. Paris: Denoel et Steele.

NOGUEIRA, Franco (1978). Salazar: as grandes crises (1936-1945). Coimbra: Atlântida Editora.

PEREIRA, Pedro Theotónio (1972). Memórias. Lisboa: Verbo, 2 vols. 
(1981). Correspondência de Pedro Theotónio Pereira para Oliveira Salazar: vol. I (1931-1939). Lisboa: Presidência do Conselho de Ministros/Comissão do Livro Negro sobre o Regime Fascista.

PRETO, Rolão (1933). Nacional Sindicalismo. Lisboa: UP.

TINOCO, António L. (1933). A revolução nacional dos trabalhadores: princípiosdoutrina. Lisboa: UP.

\section{Referências bibliográficas}

BARBOSA, Márcio (2015). Novo Estado Marcelista (1929-1974). Tese (Doutoramento em Altos Estudos em História, ramo de Época Contemporânea). Universidade de Coimbra, Coimbra.

BRANCO, Rui (2017). Entre Bismarck e Beveridge: Sociedade Civil e EstadoProvidência em Portugal (1960-2011). Análise Social, vol. 52, n. 224, pp. 534558.

FORTI, Steven (2016). Reptos dos trânsfugas: biografia e análise da linguagem política numa perspectiva comparada. In: NEVES, José (org.). Quem faz a história: ensaios sobre o Portugal contemporâneo. Lisboa: Edições Tinta-da-China, pp. 123-132.

FREIRE, Dulce; FERREIRA, Nuno Estevão. A construção do sistema corporativo em Portugal (1933-1974). Tempo, vol. 25, n. 1, pp. 256-276.

GARRIDO, Álvaro (2016). Queremos uma economia nova!: Estado Novo e corporativismo. Lisboa: Temas \& Debates/Círculo de Leitores.

LEAL, Ernesto Castro (1999). Nação e nacionalismos: a Cruzada Nacional D. Nuno Álvares Pereira e as origens do Estado Novo (1918-1938). Lisboa: Edições Cosmos.

LICHTERMAN, Paul; CAFAI, Daniel (2006). The idea of political culture. In: GOODIN, Robert E.; TILLY, Charles (ed.). The Oxford Handbook of Contextual Political Analysis. Oxford: Oxford University Press, pp. 392-415.

MARTINHO, Francisco Carlos Palomanes (2016). Marcello Caetano: uma biografia, 1906-1980. Lisboa: Objectiva.

MARTINS, Fernando (2004a). Historiografia, biografia e ética. Análise Social, vol. XXXIX, no 171 , pp. 391-408.

. (2004b). Pedro Theotónio Pereira: uma biografia (1902-1972). Tese (Doutoramento em História). Universidade de Évora, Évora.

MENESES, Filipe Ribeiro de (2010). Salazar: uma biografia política. Lisboa: Publicações Dom Quixote.

MESQUITA, António Pedro (2007). Salazar na história política do seu tempo. Lisboa: Editorial Caminho.

PINTO, António Costa (1994). Os Camisas Azuis: ideologia, elites e movimentos fascistas em Portugal, 1914-1945. Lisboa: Editorial Estampa.

PIRES, Leonardo Aboim (2016). João Pinto da Costa Leite (Lumbrales) na construção do modelo económico do Estado Novo: pensamento e ação política. Revista de História da Sociedade e da Cultura, vol. 16, pp. 393-412.

REIS, Joana (2013). Melo e Castro: o provedor que dizia sim à democracia. Lisboa: Casa das Letras.

RODRIGUES, Luís Nuno (1996). A Legião Portuguesa: a milícia do Estado Novo (1936-1944). Lisboa: Editorial Estampa.

ROSAS, Fernando (2013). Salazar e o poder: a arte de saber durar. Lisboa: Tinta-daChina. 
ROSAS, Fernando (2019). Salazar e os fascismos. Lisboa: Tinta-da-China.

SARDICA, José Miguel (2013). The content and form of 'conventional' historical biography. Rethinking History: The Journal of Theory and Practice, vol. 17, $\mathrm{n}^{\mathrm{o}}$ 3, pp. 383-400.

SANTOMASSIMO, Gianpasquale (2006). La terza via fascista: il mito del corporativismo. Roma: Carocci Editore.

SERAPIGLIA, Daniele (2006). Un corporativista portoghese in Italia: António Castro Fernandes. In: PASETTI, Matteo (ed.). Progetti corporativi tra le due guerre mondiali. Pisa: Carocci Editore, pp. 99-110.

VALENTE, José Carlos (1999). Estado Novo e Alegria no Trabalho: uma história política da FNAT (1935-1958). Lisboa: Colibri.

Artigo recebido em 12 de fevereiro de 2020.

Aprovado em 09 de junho de 2020.

DOI: 10.12957/intellectus.2020.48428 